\title{
INADEQUAÇÕES ERGONÔMICAS EM HABITAÇÕES POPULARES REFORMADAS: UM ESTUDO DE CASO COM USUÁRIOS INFANTIS
}

\author{
SILVA, Aniele Marques (1);
}

SILVA, Vanessa Karol (2);

SOUZA, Waléria Alves (3);

\section{BARROS, Bruno (4)}

(1) UFPE, Graduanda em Design

e-mail: anielemarquess@gmail.com

(2) UFPE, Graduanda em Design

e-mail: vanessakarolufpe@gmail.com

(3) UFPE, Graduanda em Design

e-mail:waleria.as@gmail.com

(4) UFPE, Mestre

e-mail: barros bruno@hotmail.com

\begin{abstract}
RESUMO
Comumente, famílias de baixo poder aquisitivo são convidadas a deixarem seus lares sob a promessa de uma moradia melhor, no entanto, os conjuntos de moradias padronizadas desconsideram as necessidades particulares de cada família. Tais necessidades acabam estimulando reformas inconsistentes na edificação, as quais acarretam o aumento de inadequações ergonômicas. A corrente pesquisa teve o objetivo de analisar um dormitório de uma edificação reformada, o qual é de uso infantil. Alicerçamo-nos na Metodologia para Projetos de Construção Centrados no Ser Humano proposta por Attaianese e Duca (2012). Através da análise da edificação, estabeleceram-se critérios projetuais e uma nova proposta de ambiente.
\end{abstract}

Palavras chave: ergonomia do ambiente construído; edificações adaptadas; habitações populares.

\begin{abstract}
Nowadays, it is possible to realize that low-income families are compelled to leave their homes under the promise of a better home, however, standardized housing sets do not consider the particular needs of each family. Such needs imply inconsistent building reforms, which lead to increased ergonomic failures in the built environment. The current research was aimed at analyzing a bedroom in a reformed building, which is used by children. We are based on the Methodology for HumanCentered Construction Projects proposed by Attaianese and Duca (2012). As a result of the building analysis, design recommendations were established and a new proposal was proposed for an ergonomically appropriate environment.
\end{abstract}

Keywords: built environment ergonomics; refurbished buildings; humble housing. 


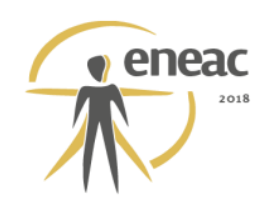

\section{INTRODUÇÃO}

No século passado, por motivos urbanísticos e sanitários, gestores demoliram diversos cortiços e desabrigaram seus moradores em decorrência do crescimento das grandes cidades. Este contexto social alavancou o incipiente processo de favelização, na ausência de abrigo, muitos moradores acabaram elevando a população de favelas. Com o intuito de reduzir a quantidade de favelas, desenvolveram-se políticas de remoção, onde os moradores são, na grande maioria, enviados para conjuntos habitacionais localizadas em regiões distantes do centro. Muitas vezes o processo é conduzido com muita brutalidade, desde o anúncio da remoção. No Brasil, a construção de conjuntos habitacionais acompanhou paralelamente a remoção das famílias de comunidades carentes, contudo, a construção desses conjuntos habitacionais não resolveu o problema da habitação popular, mas infelizmente levou uma demanda grande de pessoas para locais onde não havia a infraestrutura necessária.

Dentro deste contexto, surgiu a essência investigativa desta pesquisa, a qual repousou o foco no acompanhamento de uma família que passou pelo processo de transição de moradia. Devido à distância da localização da habitação, um dos moradores precisou largar o emprego e, na imprescindibilidade de adquirir renda, se viu na necessidade de realizar uma reforma na edificação, abrindo um pequeno salão de beleza. A reforma não foi estruturada por arquitetos ou engenheiros, mas por pedreiros da região. O planejamento de reforma se deu de modo informal, onde as decisões foram tomadas em conversas com os operários no local da edificação destinado às alterações. As mudanças realizadas comprometeram o desempenho de outros cômodos da moradia, em especial o dormitório localizado ao lado do salão, o qual é ocupado por duas crianças e tem sua função para além de simplesmente dormir.

A utilização de dormitórios faz parte do cotidiano de qualquer usuário, por isso é relevante que esse cômodo não dificulte ou prejudique seus usuários fisiológica ou psicologicamente. Em caso de dormitórios infantis, além de pensar em elementos atrativos para as crianças, é importante levar em consideração a segurança e manutenção da saúde desses usuários. A ergonomia tem o papel de oferecer ambientes que atendam às necessidades dos indivíduos que o utilizam. Nesse sentido, é primordial entender a necessidade e o problema que o usuário está enfrentando ao interagir com o sistema em questão. Sendo assim, apoiamonos na Metodologia para Projetos de Construção Centrados no Usuário para propor soluções de otimização do ambiente do dormitório utilizado por duas crianças.

\section{FUNDAMENTAÇÃO TEÓRICA}

Ao inserir o ser humano e a sociedade neste mundo, ocorrem as transformações efetuadas por eles no espaço para melhorar a sua ocupação, o seu habitar. Assim, chega-se ao conceito de lugar de Heidegger (1954), "[...] o lugar, é a porção tangível do espaço, apreensível pela experiência cotidian" (SCOARIS, 2012, p.45).

Segundo Scoaris (2012), o arquiteto norueguês Norberg-Schulz (2008) define o lugar de duas formas, a saber, estrutura do lugar e espírito do lugar. A estrutura é apresentada de duas maneiras sendo elas espaço e caráter. Temos o espaço determinado pelas limitações físicas impostas pela edificação e o caráter é a atmosfera transmitida por ele. Este último se conecta também às qualidades sensoriais dos materiais que definem o espaço. Já o espírito do lugar é identificado como o potencial, a vocação de um espaço, abrangendo também os aspectos que se relacionam com sua identificação e oferecem sentimento de pertencimento. Isto implica em criar possibilidades espaciais que facilitem, contribuam para que o homem possa exercer suas atividades cotidianas de forma mais eficiente, confortável e adequada para os diferentes fins aos quais elas se destinam, seja no trabalho ou no descanso. Em 


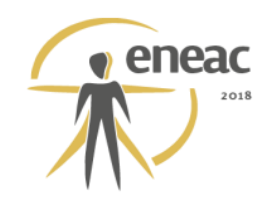

outras palavras, atribuir características a edificação que agreguem mais qualidade ao habitar do indivíduo.

De acordo com Páscoa (2008), o ser humano pode conhecer o seu meio através do espaço de modo íntimo, que aos poucos o transforma em Lugar. A autora explica que este seria um conhecimento aprendido e vivenciado por meio de particularidades e experiências das ideias percebidas pelos sentidos sensoriais e elaboradas mentalmente, fator que torna o Lugar cada vez mais único, uma vez que cada indivíduo tem um universo diferente de características pessoais e de vivências peculiares. Na realidade, Espaço e Lugar estão muito próximos e, segundo Tuan (2013) "o Lugar é o Espaço ocupado e vivido". Desta forma, podemos entender que a transformação do espaço em lugar domiciliar se dá na medida em que este é vivenciado pela família de moradores, os quais se desenvolvem nele sob influência de seus valores e culturas.

Ao se apropriar de um lugar, estabelecendo nele o seu habitar, o homem busca modificá-lo à medida que lhe é mais conveniente. Essas modificações podem envolver aspectos físicos da edificação, com mudanças em formas dos ambientes, aberturas, cobertura e revestimentos, como também do mobiliário contido em seus ambientes. Tomando como exemplo um edifício de uso multifamiliar, onde as várias unidades habitacionais possuem a mesma forma arquitetônica, temos em cada uma das residências exemplares únicos e personalizados de habitação. Isto pode ser explicado pelo fato de que, para cada indivíduo, o habitar doméstico é percebido e vivenciado de maneira diferente, praticamente pessoal, principalmente em relação ás suas próprias casas.

No momento em que o arquiteto define como serão as residências de um conjunto habitacional, ele apenas definiu espacialmente os lugares que compõem a habitação. Ou seja, ele definiu a moradia e como seus diferentes espaços se relacionam, sem limitar totalmente como o usuário fará uso destes espaços. Camargo (2010) em suas reflexões afirma que "nenhuma das soluções espaciais que adotarmos para uma moradia será totalmente adequada, uma vez que as necessidades, expectativas e aspirações dos moradores com relação a sua moradia manifestam-se com o ato de morar" (CAMARGO, 2010, p. 12-13).

Faz-se necessário investigar o que realmente a função do ambiente engloba para, com isso, se evitar ao máximo grandes alterações pós-ocupação na edificação. Por exemplo, ao se projetar um dormitório individual não seria correto definir que a única função exercida naquele espaço é a de dormir, principalmente considerando o perfil da atual sociedade multitarefa, onde se realiza várias atividades ao mesmo tempo. Várias pessoas navegam na internet enquanto conversam nos telefones celulares ao mesmo tempo em que assistem a seus programas favoritos na televisão, tudo isso, em muitos casos, deitados no conforto de suas camas em seus dormitórios. Isto é apenas um exemplo em escala menor, pois ao se estender esse raciocínio a complexidade que envolve as várias funções exercidas por diferentes ambientes numa moradia, inclusive as áreas externas, é possível atingir o problema em escala bem maior.

\section{METODOLOGIA}

A pesquisa foi guiada através da Metodologia para Projetos de Construção Centrados no Ser Humano, apresentada por Attaianese e Duca (2012). A investigação lançou mão das quatro primeiras etapas da metodologia, que consiste no: Briefing de Design, Perfis de Usuários e Grupo de Ajuste, Análise da Tarefa e Adaptação às Necessidades dos Usuários.

O Briefing de Design, primeira etapa da metodologia, tem foco na coleta de informações a respeito do ambiente. Para isso foi realizado uma entrevista com os usuários do ambiente, com questionamentos que permitisse a sondagem a respeito da percepção do usuário sobre 


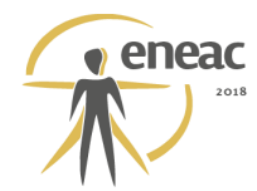

o ambiente estudado.

A segunda etapa da metodologia, denominada de Perfis de Usuários e Grupo de Ajuste, consiste na coleta de dados a respeito dos usuários do ambiente. Busca-se identificar o perfil dos usuários diretos, ou seja, os usuários que utilizam o ambiente frequentemente; e também os usuários indiretos, que são aqueles que eventualmente fazem uso do ambiente.

A terceira etapa, Análise da Tarefa, permite investigar as atividades realizadas na edificação que apresenta inadequações, verificando as posturas adotadas pelos usuários durante a realização dessas atividades e fazendo considerações acerca dos riscos das posturas observadas de acordo com a Ergonomia. Nesta fase adicionamos aferições de conforto ambiental (a partir dos indicadores de iluminação, ruído e temperatura).

A quarta e última etapa, que diz respeito a Adaptação às Necessidades dos Usuários, consiste na síntese de todos os problemas encontrados na edificação, ressaltando as adaptações necessárias e recomendações ergonômicas que atendam às necessidades especificas de seus usuários.

\section{RESULTADOS}

\subsection{Briefing de Design}

O ambiente selecionado para estudo de caso é um dormitório compartilhado por dois irmãos. O espaço tem uma área de $6 \mathrm{~m}^{2}$ e o PD de $2,50 \mathrm{~m}$ e possui duas esquadrias, sendo uma porta sanfonada de PVC, que encontra-se danificada, e uma janela de duas folhas de madeira e vidro. Embora haja uma janela não há ventilação no quarto, uma vez que a janela está direcionada para outro ambiente da residência. O quarto possui cores monótonas e é pouco acessível devido a quantia e a disposição de seus elementos internos.

Para a coleta de informações a respeito do ambiente estudado foi aplicado um questionário para um dos usuários diretos do ambiente, uma menina de 12 anos (que será retratada ao longo da pesquisa como usuária 1). O questionário buscou informações como: se existia alguma forma de dificuldade de acesso no dormitório, se os objetos utilizados podiam ser alcançados com facilidade, quais eram as principais dificuldades encontradas no ambiente, quais eram os itens ela gostaria que existisse no dormitório e se teria algum elemento que ela considerava desnecessário no ambiente.

Figura 1 - Imagem do ambiente selecionado para estudo de caso.
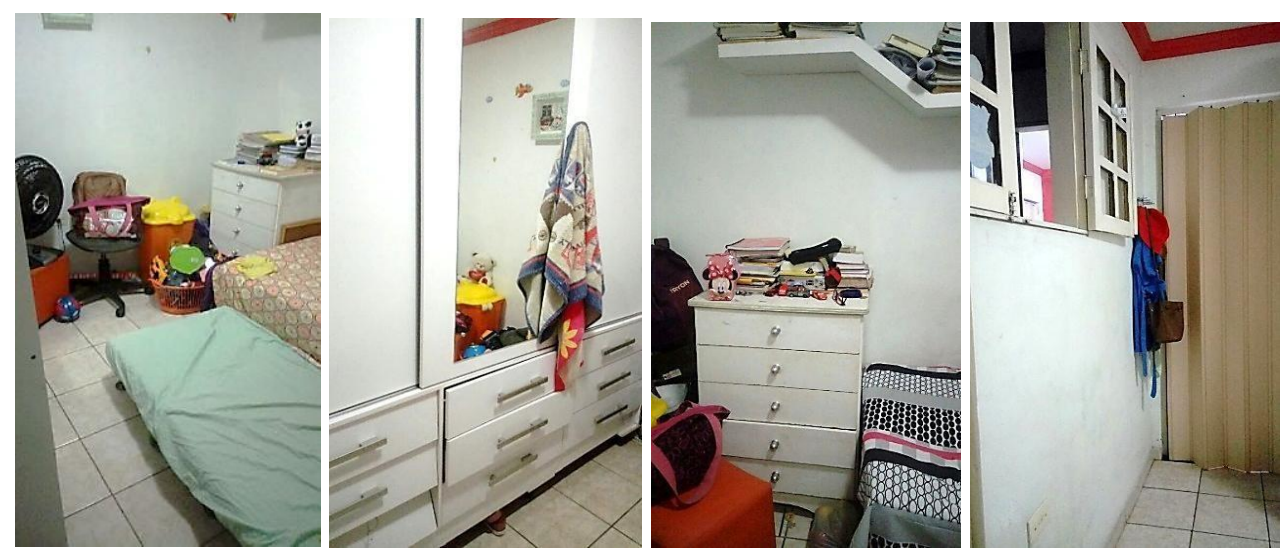

Fonte: Capturado pelos autores para a pesquisa. 


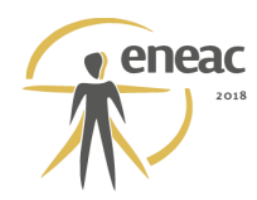

Em relação à circulação, a usuária relatou sentir dificuldade de locomoção em determinados locais do ambiente, principalmente quando a gaveta da cama box auxiliar estava aberta. No que diz respeito aos alcances de artefatos no ambiente, a usuária revelou sentir dificuldade para pegar os livros que ficam em cima da cômoda, pois os brinquedos de seu irmão são guardados em um cesto que fica em frente a cômoda. Ela também relatou que é difícil pegar ou guardar livros na prateleira localizada acima da cama e para alcançar as partes mais altas do roupeiro.

Para a usuária 1, os principais problemas do ambiente são o demasiado calor e a quantidade de objetos no ambiente o qual ela considera pequeno. Ao ser questionada sobre quais elementos a usuária gostaria que tivesse no dormitório, foi respondido que ela gostaria de uma mesa e de uma cadeira que servissem de apoio para os seus estudos.

Esse mesmo questionário não pôde ser aplicado ao segundo usuário direto do ambiente, usuário 2, pois trata-se de um garoto com apenas 4 anos de idade e não saberia responder a complexidade de tais perguntas. Contudo suas necessidades também foram levadas em consideração na realização do projeto. Para tanto, buscou-se respaldo na literatura para entender as necessidades deste usuário e aplica-las no projeto.

\subsection{Perfis dos Usuários}

A primeira usuária direta do ambiente estudado é uma menina de 12 anos e o segundo usuário direto é um menino de 4 anos. Os usuários diretos utilizam o ambiente como um local de estudos, de lazer, de armazenamento de utensílios pessoais e de descanso. Além dos usuários diretos, há os usuários indiretos que no caso se tratam dos pais das crianças, os quais utilizam o ambiente para guardar algum objeto ou limpar o espaço.

Existem dificuldades em fazer um projeto visando melhorias ergonômicas sem levar em consideração as limitações dos usuários a quem o projeto é destinado. Nesse sentido é importante conhecer as limitações psicofisiológicas dos usuários do dormitório em estudo, a fim de que seja possível projetar um ambiente que promova conforto, bem-estar e segurança. Uma vez que os usuários são crianças, é importante considerar suas limitações de estatura. Os elementos do ambiente devem ter altura e largura que não dificultem seu alcance. Além disso, a estatura é um elemento que precisa ser analisado com cautela, pois está relacionada a segurança. No caso do usuário 2, é importante deixar fora de seu alcance os elementos que ele não pode utilizar e proporcionar fácil acesso àqueles que ele precisa utilizar com frequência.

Ambos os usuários diretos apresentam recorrentes crises de rinite alérgica, que se trata de uma reação imunológica do corpo contra partículas estranhas. O acúmulo de poeira pode ser um fator que impulsiona tal enfermidade. Desta forma, um ambiente ideal para esses usuários deve possuir revestimentos e mobiliário que promovam facilidade de limpeza e manutenção. Cabe destacar que a usuária 1 foi recentemente diagnosticada com Miopia, que se trata de uma condição onde o indivíduo acometido possui dificuldade de enxergar objetos distantes. Tendo em vista tal limitação, é necessário que o ambiente tenha uma iluminação adequada as atividades que serão realizadas no ambiente. Caso o índice de iluminância seja demasiado ou inferior ao recomendado, a usuária possuirá dificuldade para focar um objeto.

Além dos fatores fisiológicos, os psicológicos também precisam ser levados em consideração. Os usuários 1 e 2 considerados como hiperativos, tendem a possuir dificuldade de conseguir concluir tarefas, problemas de organização, dificuldade de atenção, ansiedade, impulsividade e criatividade. O dormitório é um ambiente onde eles brincam, descansam e aprendem, assim é importante que o ambiente possua elementos que produza 


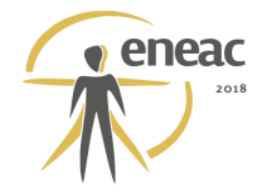

lucidez, criatividade, todavia também disponha atratividade para realização das atividades que requer atenção, como por exemplo, a elaboração das atividades escolares.

\subsection{Análise da Tarefa}

O dormitório investigado serve como suporte para execução de uma série de atividades para os usuários. As crianças o utilizam para armazenar e pegar seus utensílios pessoais, dormir, brincar, trocar de roupa, abrir a janela, acender a luz, ligar o ventilador e arrumar a cama. Cabe destacar que a usuária 1 também o utiliza como local de estudo, lendo livros e realizando as atividades extraclasse solicitadas pela instituição de ensino a qual está vinculada. Desta forma, a partir de observações sistemáticas no local, foram identificadas e analisadas as posturas assumidas pelos usuários durante a realização das atividades no ambiente, descritas nos tópicos que se seguem.

\subsubsection{Abrir a janela}

Os usuários do dormitório não conseguem abrir a janela através do interior do dormitório, pois ela não possui uma pega que auxilie essa ação (Figura A). De modo que para abrir a janela do dormitório, é necessário abrir os ferrolhos no interior do dormitório, ir para o salão de beleza, que é o cômodo que a janela dá e empurrá-la de lá. A usuária 1 (Figura B) para consegui alcançar o ferrolho superior no interior do cômodo, precisa ficar na ponta dos pés e estender seu membro superior o máximo acima da altura dos ombros. Caso os ferrolhos já estejam abertos e o usuário 2 tente abrir a janela (Figura $\mathrm{C}$ ) ele precisa subir na cadeira do lavatório para conseguir abri-la.

Figura 2 - Usuários 1 e 2 abrindo a janela.

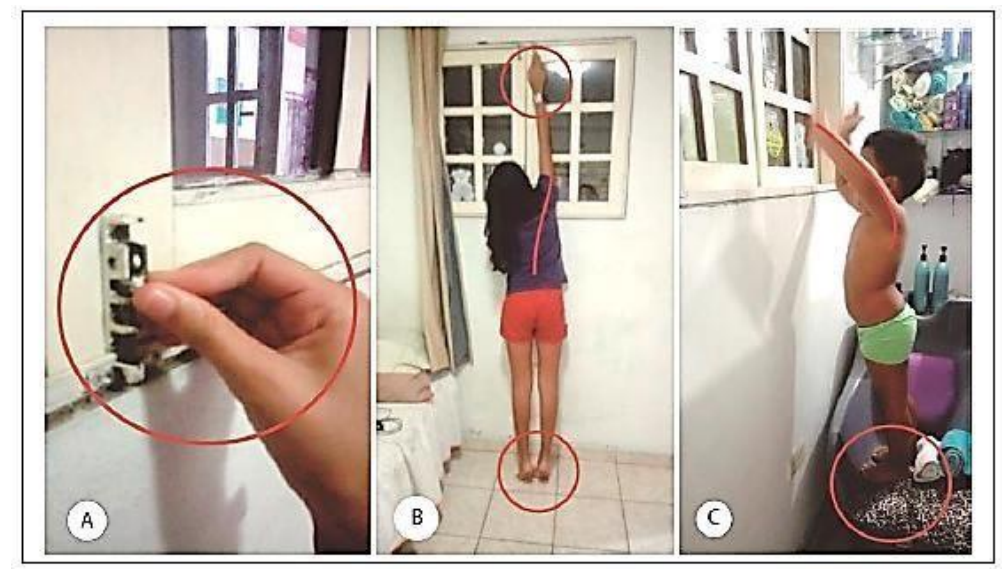

Fonte: Capturado pelos autores para a pesquisa.

Para abrir os ferrolhos da janela, a usuária 1 usa uma pega de alta precisão do tipo pinça de manejo fino, porém por causa da forma e material do ferrolho, pode ocorrer acidentes resultando em cortes ou bolhas nos dedos. A extensão feita pela usuária 1 para alcançar os ferrolhos superior da janela pode causar dores ou desconfortos nos ombros, braços e escapula superior. No caso do usuário 2 a postura observada pode causar acidente, caso algo provoque um desiquilíbrio e ele caia da cadeira. Além disso, seus membros superiores estão elevados acima da altura do ombro, podendo provocar dores nos ombros. 


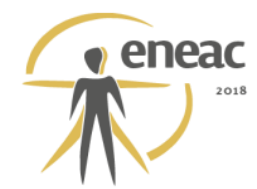

\subsubsection{Estudar}

Como no dormitório não existe uma mobília em que a usuária possa utilizar em seus estudos, ela exerce tal atividade em cima da cama. Nesta postura é possível observar a flexão do tronco, inclinação da cabeça para frente, flexão do antebraço sem apoio, forçando a musculatura do braço a sustenta-lo.

Figura 3 - Usuária 1 realizando suas atividades escolares.

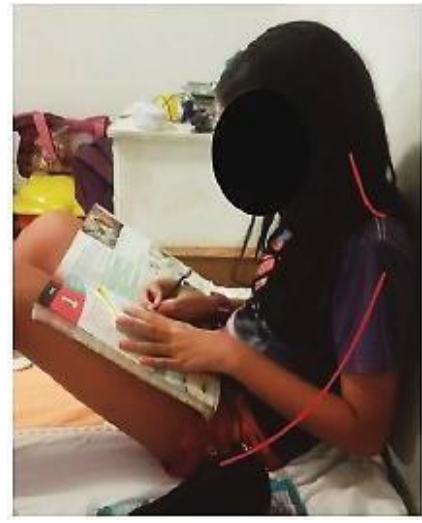

Fonte: Capturado pelos autores para a pesquisa.

A manutenção dessa postura durante horas de estudos pode provocar dores e desconforto nos ombros, região lombar, músculos da espinha eretora, musculatura do braço e fadiga muscular do pescoço e ombros por causa da inclinação do pescoço ser superior a 30‥

\subsubsection{Armazenamento de lençóis e uso da prateleira}

Devido a altura elevada dos mobiliários do quarto. A usuária 1 possui dificuldade de alcance tanto na parte superior do roupeiro (Figura A), como também no uso da prateleira. Na primeira situação a usuária utiliza o seu alcance vertical total e também fica na ponta dos pés. Já na segunda situação (Figura B), para pegar os livros a usuária precisa subir na cama, elevar os membros superiores e flexionar seu tronco para frente.

Figura 4 - Usuária 1 realizando suas atividades escolares.

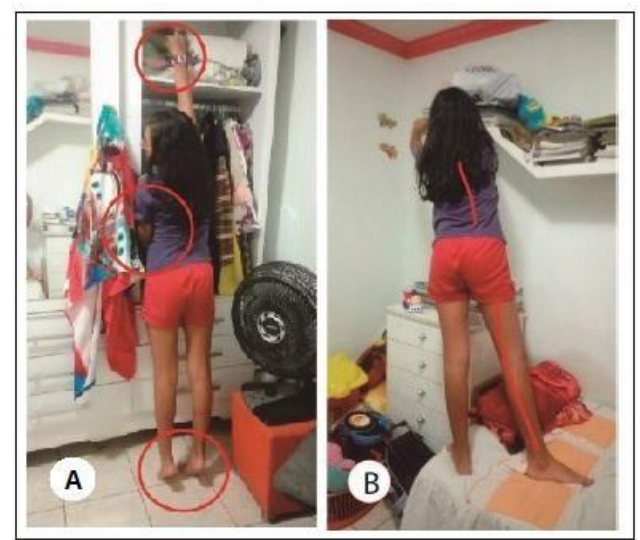

Fonte: Capturado pelos autores para a pesquisa. 


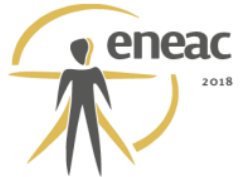

Em ambas as situações como membros superiores da usuária ficam elevados, a permanência nessa postura pode gerar dores nos ombros e na musculatura do braço. A flexão do tronco pode provocar dores e desconforto na região lombar. Além disso, é recomendável que ao ser submetido a pegar uma carga de peso, manter a carga próxima ao corpo, pois o aumento da distância entre as mãos e o corpo é proporcional ao aumento do esforço osteomuscular da região inferior das costas e dos membros superiores.

\subsection{Considerações Sobre Conforto Ambiental}

Durante essa etapa com o auxílio de instrumentos devidamente calibrados foram recolhidas medidas em horários diferentes para que pudéssemos comparar com as recomendações da ABNT e da NBR.

Para medições de iluminação foi utilizado um lluminômetro adequadamente calibrado. As medições foram feitas em três horários diferentes: as 7h30, 13h00 e 19h30, todos com a lâmpada acesa (uma vez que o ambiente é demasiado escuro e só se apaga a lâmpada no momento de dormir). Os resultados se mostraram muito abaixo do recomendado, com o mínimo de 10 e o máximo de 58lux. Nenhum dos resultados obtidos foi satisfatório em relação à recomendação da NBR 5413, que define índices de iluminância adequados para dormitórios entre 100-150-200lux. O baixo índice de iluminância pode causar acidentes durante o uso de artefatos ou até mesmo na circulação do ambiente, tais resultados também são agravantes uma vez que a usuária 1 possui limitação da capacidade visual, podendo acentuar seu problema.

Para a verificação dos índices de temperatura foi utilizado termômetro digital rigorosamente calibrado. Os índices foram analisados em três horários distintos, sendo eles: as $7 \mathrm{~h} 30 \mathrm{da}$ manhã, onde se obteve como resultado da aferição $30^{\circ} \mathrm{C}$; às $13 \mathrm{~h} 00$ da tarde, onde foi verificado $33^{\circ} \mathrm{C}$; e às $19 \mathrm{~h} 30$ da noite, onde se identificou uma temperatura de $29^{\circ} \mathrm{C}$. É importante considerar que no ambiente em estudo não há ar condicionado, mas existe uma janela e um ventilador, mesmo assim em relação aos resultados obtidos, independente do horário, todos os níveis de temperatura estão acima da recomendação entre $20-23^{\circ} \mathrm{C}$ da NBR17.

Utilizando um decibelímetro devidamente calibrado, foi feita a avaliação dos níveis de ruídos no ambiente, durante às $7: 30 \mathrm{~h}, 13 \mathrm{~h}$ e $19 \mathrm{~h}$. A casa é localizada em um bairro que possui muita movimentação durante a manhã, devido a venda de produtos alimentícios em carros. De acordo com a NBR10152 de níveis de ruído para conforto acústico, o nível de ruído indicado para dormitórios é de $35-45 \mathrm{Db}$. De acordo com as medições realizadas no dormitório, observa-se que durante a manhã obteve-se resultados entre 52-55Db, acima do recomendado pela norma. Durante a tarde e à noite, os índices de ruído estavam dentro dos padrões da norma.

\subsection{Adaptações às Necessidades dos Usuários}

Sob o foco da melhoria do espaço, à luz das características e limitações dos usuários, os dados coletados na pesquisa foram analisados cautelosamente. Os problemas no ambiente foram identificados e, através de análises, estabeleceram-se recomendações corretivas e adaptativas, descritas no tópico que se segue. 


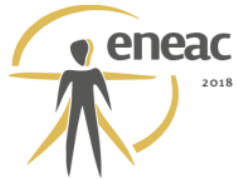

\subsubsection{Recomendações ergonômicas}

A verificação desses problemas no ambiente permitiu estudos para geração de recomendações, as quais focaram na solução de problemas e, consequentemente, na melhoria das condições de desempenho de atividades no ambiente estudado. Tais recomendações serão apresentadas na lista a seguir:

- Propor cama beliche para os usuários, a fim de otimizar o espaço horizontal para realização de outras atividades;

- Indicar a cama superior do beliche para a usuária 1 e a inferior para o usuário 2, pois as camas beliches não são indicadas para crianças com menos de 6 anos.

- Dispor de um interruptor paralelo próximo a cama superior, de modo que a usuária 1 possa aciona-lo caso precise descer da cama no meio da noite, evitando que ela tente desce-la no escuro;

- Aumentar a luminosidade, com iluminação embutida em todo a roda teto do quarto, e luminária embutida no teto, centralizada, na cor amarela, tornando o ambiente mais aconchegante e confortável;

- Dispor luminária lateralmente ao local de estudo, sobre a mesa, para proporcionar luz direcionada para atividade que requer concentração da usuária, com uso de lâmpada LED ou fluorescente de cor amarela. Selecionar uma lâmpada fria e que seja confortável para a visão;

- Substituir o ventilador atual por um ar condicionado Split, a fim aumentar o espaço horizontal;

- Optar por estética minimalista para transmitir organização, harmonia e amplitude, uma vez que a circulação horizontal do ambiente é restrita;

- Dispor de mesa e cadeira para servirem de suporte para os estudos. A mesa serve para estudar e armazenar os livros da usuária 1. A cadeira indicada deve ser acolchoada e possuir um encosto que permita a mudança de postura, a fim de prorrogar o aparecimento de fadiga. Contando também com regulador de altura de assento e do braço da cadeira para que seja adaptável ao crescimento da usuária.

- Aplicar a cor amarela na mesa de estudo, a qual estimula a aprendizagem, criatividade e a concentração;

- Dispor de roupeiro $60 \mathrm{~cm}$ mais baixo que a altura atual, adequando-o antropometricamente aos seus usuários. Propor um novo layout para o roupeiro, o qual disponha de melhor distribuição do espaço para organização dos objetos pessoais dos usuários;

- Aplicar puxadores do roupeiro maior, para que o usuário 2, de menor estatura, possa utilizá-lo com maior eficácia;

- Os puxadores do roupeiro, janela e porta devem ser embutidos para diminuir o risco de acidentes dos usuários no ambiente. Também recomenda-se que todos estes puxadores sejam em cores diferenciadas da superfície ao qual estão inseridos, para que possam ser melhor visualizados;

- Propor fechadura da janela com formato de trava com material plástico, para diminuir os ricos de acidentes dos usuários e também posicionar a fechadura em uma altura mais baixa que a atual, tornando-a antropometricamente acessível para ambos os usuários;

- Substituir a janela de duas folhas por uma de madeira veneziana para otimizar o 


\section{(x) $^{\text {enack }}$}

espaço horizontal do ambiente e também promover a circulação do ar, mesmo quando a janela estiver fechada, de modo que auxilie a sensação térmica ambiental. Propor mudança de posição da janela, uma vez que a atual tem abertura para outro ambiente fechado (salão de beleza);

- Substituir a cortina de plástico atual por uma cortina persiana romana blackout, devido a mudança da posição da janela, irá existir uma influência de luminosidade maior que pode atrapalhar um possível descanso dos usuários durante o dia;

- Utilizar protetor de tomada para evitar acidentes elétricos que envolvam o usuário 2;

- Melhorar a disposição do mobiliário, reduzindo a quantidade de elementos dispostos no quarto, através do aproveitamento do espaço vertical, de modo que a circulação do quarto seja melhorada;

- Utilizar piso cerâmico, uma vez que o ambiente é localizado numa região de clima quente. Além disso, o piso cerâmico é fácil de limpar e não mancha com facilidade. Aplicar piso na cor cinza, optada por ser uma cor neutra para que ele não fique desarmônico com as outras cores utilizadas no ambiente. Instalar forro de teto com revestimento de gesso plano na cor branca, diminuindo o acúmulo de poeira;

- Optar por revestimentos melamínicos de baixa pressão na cor branca no roupeiro e nas camas (promovendo a iluminação do ambiente), pois é um revestimento mais resistente que o Finish Foil;

- Revestir as paredes com as cores cinza e verde, para transmitir sensação de frescor e tranquilidade no dormitório. Aplicar papel de parede com listras na cor branca e cinza em uma das paredes, promovendo a sensação de amplitude no espaço;

- Indicar o uso de mobília sem quinas vivas para garantir a segurança dos usuários infantis.

Ao considerar as recomendações ergonômicas estabelecidas, tornou-se possível elaborar um projeto conceitual como modelo de orientação para alterações necessárias ao ambiente, apresentado através da figura a seguir:

Figura 5 - Rendering do projeto conceitual para o ambiente.

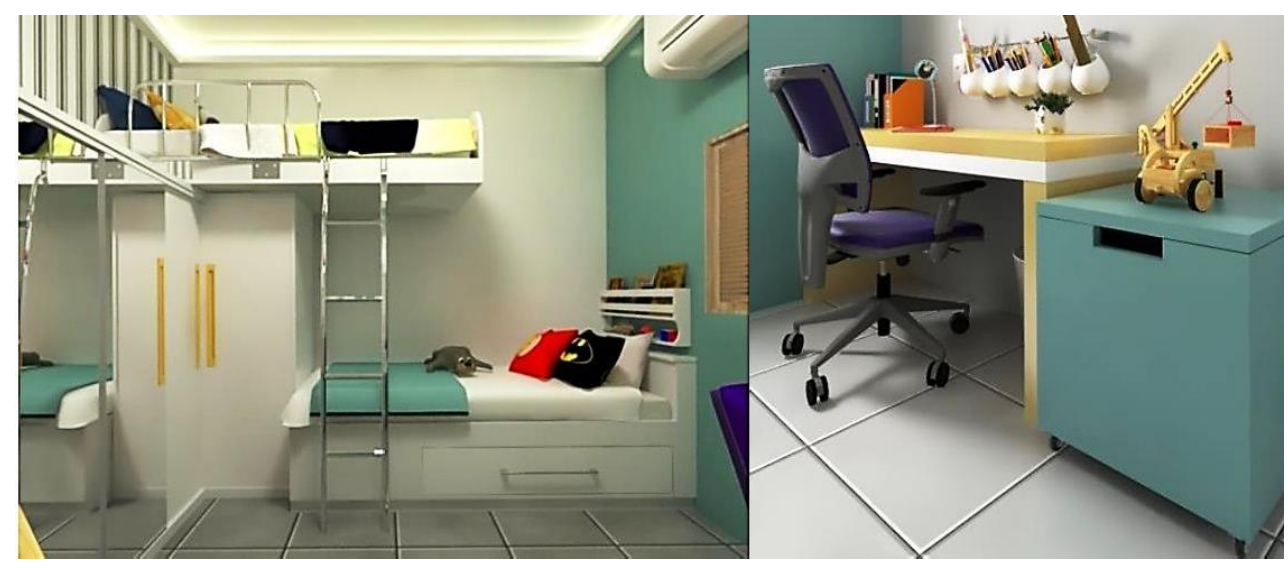

Fonte: Capturado pelos autores para a pesquisa.

Através da aplicação da cama beliche e do posicionamento de parte do roupeiro abaixo da cama superior, foi possível otimizar a circulação horizontal do ambiente. Tal melhoria permitiu a inserção de mobiliários que faltavam no ambiente, como é o caso da mesa de 
estudos para a usuária 1.

O projeto também procurou solucionar os problemas encontrados na verificação do conforto ambiental, de modo que foram inseridos mais pontos de iluminação no ambiente e também foi proposta a mudança do posicionamento da janela, a fim de gerar ventilação interna no quarto. Além disso, também foi proposta a adição de um ar condicionado, com o propósito de que a temperatura ambiental fosse amenizada. Ao fim da pesquisa, o projeto conceitual foi detalhado e entregue impresso à família, juntamente com a oferta de apoio gratuito no acompanhamento da realização das adequações. A proposta de reforma foi aceita pela família e o processo de reestruturação está em fase inicial. Ao término das alterações no espaço, uma nova avaliação no ambiente será realizada, sob o foco de verificação do índice de adequação ergonômica do projeto executado.

\section{CONCLUSÃO}

Ações políticas de remoção de famílias devem ser, no mínimo, acompanhadas por um complexo sistema de gestão participativa de transição de moradia, o qual capte as necessidades dos moradores, bem como forneça apoio psicológico durante e após a transição para um novo lar. A decisão de remover famílias não deve partir de estratégias sociais de convivência segregada ou de desocupação de áreas de grande valor imobiliário.

Quando refletimos sobre a razão das incidências dos problemas ergonômicos encontrados no estudo de caso descrito nesta publicação, imediatamente nos vêm à mente a falta de planejamento urbano, no entanto o planejamento definitivamente existe e é bastante elaborado, mas com objetivos alheios às considerações humanas de projeto. Acreditamos que o maior foco tem sido o da priorização do interesse do capital na construção e ocupação da cidade. A pesquisa nos ressalta a reflexão de que é necessário mudar o consciente que privilegia a especulação imobiliária em detrimento do direito à moradia digna.

Através da pesquisa foi possível observar as dificuldades que os usuários da pesquisa encontravam para realizar tarefas cotidianas em um quarto que, nitidamente, não foi projetado visando o conforto e o bem-estar de seus usuários. A pesquisa também possibilitou perceber a importância de conhecer o usuário a quem se destina um projeto de ambientação. Pois a partir desse conhecimento é possível identificar os problemas do ambiente construído e propor recomendações que atendam às necessidades especificas daqueles usuários.

O trabalho mostra a importância de se realizar um projeto de ambientação prevendo as dificuldades que o usuário possa vir a sentir ao utilizar o ambiente e pesquisar formas de soluciona-las antes que problemas ocorram. $O$ isolamento da edificação demandou uma reforma, transformando um espaço do domicílio em salão de beleza, o que comprometeu a qualidade do desempenho das atividades no dormitório das crianças que residem na casa. Um dos fatores que mais saltaram aos olhos foi a disposição da janela do dormitório (voltada para o salão), a qual não se evitava abrir no intuito de impedir excesso de ruído. Com isso, o dormitório não apresentava circulação de ar por meio de uma ventilação cruzada, elevando a temperatura do ambiente e promovendo a proliferação de fungos e bactérias.

Os dados deste estudo elucidam não somente os problemas da edificação doente analisada, mas também enaltece o fato de que, apesar da difusão e consolidação da Ergonomia enquanto área de atuação, pesquisas na área da Ergonomia do Ambiente Construído ainda se fazem deveras necessárias. Fica clara a relevância da Ergonomia como foco de projetos de habitações populares, especialmente no que tange às composições familiares que envolvem a presença de crianças. 


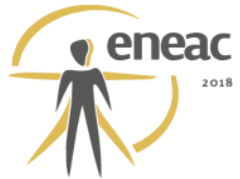

\section{REFERÊNCIAS BIBLIOGRÁFICAS}

Associação Brasileira de Normas Técnicas. NBR 10151 - Acústica - Avaliação do ruído em áreas habitadas, visando o conforto da comunidade - Procedimento. Rio de Janeiro: ABNT, 2000.

Associação Brasileira de Normas Técnicas. NBR 10152/1999 - Níveis de ruído para conforto acústico. Rio de Janeiro: ABNT, 1987.

Associação Brasileira de Normas Técnicas. NBR 17 - Ergonomia. Rio de Janeiro: ABNT, 2007.

Associação Brasileira de Normas Técnicas. NBR 5413 - lluminação de ambientes de trabalho. Rio de Janeiro: ABNT, 1992.

CARVAlHO, Mara Campos de; SOUZA, Tatiana Noronha. Psicologia Ambiental, Psicologia do Desenvolvimento e Educação Infantil: Integração possível?. 2008. Universidade de São Paulo. Disponível em < http://www.scielo.br/pdf/paideia/v18n39/v18n39a04.pdf> acesso em: 14 nov 2017.

CHAURAND, Rosalío Avila LEÓN, Lilia R Prado MUÑOZ, Elvia L González, Dimensiones antropométricas de población latinoamericana: México, Cuba, Colombia, Chile. México: Universidad de Guadalajara, 2001.

PANERO, Julius; ZELNIK, Martin. Dimensionamento humano para espaços interiores. Barcelona: G. Gili, 2003.

ZAMBERLAN, Maria Aparecida Trevisan; BASANI, Simone Inaura Stroka. Organização do espaço e qualidade devida: pesquisa sobre a configuração espacial em uma instituição de educação infantil. Disponível em<www.pucpr.br/eventos/educere/educere2006/.../docs/PA- 328-TC.pdf> acesso em: 13 de novembro de 2017.

CAMARGO, Érica Negreiros de. Casa, doce lar: o habitar doméstico percebido e vivenciado. São Paulo: Annablume, 2010.

HEIDEGGER, Martin. Construir, Habitar, Pensar. In: Conferência da Segunda Reunião de Darmastad. Trad. Marcia Sá Cavalcante Schuback. Vortäge und Aufsätze, G. Neske, Pfullingen, 1954.

SCOARIS, Rafael de Oliveira, $\mathbf{O}$ projeto de arquitetura para moradias universitárias: contributos para verificação da qualidade espacial. São Paulo, 2012.

NORBERG-SCHULZ, C. O fenômeno do lugar, In: Uma nova agenda para a arquitetura: antologia teórica (1965-1995). NESBIT, K. (org.). 2ª ed. rev. São Paulo: Cosac Naify, 2008.

TUAN, Yi-Fu. Espaço e Lugar: A Perspectiva da Experiência. Eduel, 2013.

PÁSCOA, O. N. de F. A qualidade do lugar em escola pública padronizada do rio de janeiro. estudo de caso: escola municipal tia ciata. Dissertação de Mestrado. Programa de Pós-graduação em Arquitetura, Faculdade de Arquitetura e Urbanismo. Universidade Federal do Rio de Janeiro. Rio de Janeiro, 2008. 